\title{
Gestão de Negócios de Mídia: um meta-estudo sobre decisões estratégicas
}

\section{Media Business Management: a meta-study on strategic decisions}

\author{
Fabiano Rodrigues \\ Professor adjunto e pesquisador no Programa de Mestrado \\ Profissional em Produção Jornalística e Mercado da Escola \\ Superior de Propaganda e Marketing, São Paulo, SP, Brasil \\ ORCID: 0000-0002-0313-9492 \\ <frodrigues@espm.br>
}

\author{
Edson Capoano \\ Professor adjunto e pesquisador no Programa de Mestrado \\ Profissional em Produção Jornalística e Mercado da Escola \\ Superior de Propaganda e Marketing, São Paulo, SP, Brasil \\ ORCID: 0000-0001-6766-802X \\ <edson.capoano@espm.br>
}

\section{Como citar este artigo (How to cite this article): \\ RODRIGUES, Fabiano. Gestão de Negócios de Mídia: um meta-estudo sobre decisões estratégicas. Revista Famecos, Porto Alegre, v. 25, n. 3, p. 1-23, setembro, outubro, novembro e dezembro de 2018: ID29188. DOI: http://dx.doi.org/10.15448/1980-3729.2018.3.29188.}

\section{RESUMO}

Esta pesquisa consiste em um meta-estudo qualitativo para mapear o estado atual dos estudos envolvendo decisões estratégicas em negócios de mídia. As análises se basearam nas publicações do International Journal on Media Management. O metaestudo contemplou amostra de 25 artigos (dentre 61 artigos entre 2013 e 2017). As dimensões de análise foram: relação com a gestão estratégica; objetivos e tipo de empresa. Como resultados, destaca-se a predominância (72\%) de estudos envolvendo decisões sobre modelos de negócio e formas de financiamento. Os estudos retratam diferentes atores desta indústria, como veículos tradicionais, agregadores de mídia, jornais, plataformas de vídeos e notícias. Como contribuição, esta pesquisa avança na literatura sobre media management por meio da sistematização das indagações acadêmicas recentes sobre decisões estratégicas, apresentando categorias de análise para pesquisadores e praticantes da área de jornalismo, comunicação e administração.

Palavras-chave: Negócios de mídia. Decisões estratégicas. Gestão estratégica.

\section{ABSTRACT}

This research consists of a qualitative meta-study to map the current state of studies involving strategic decisions in media businesses. The analyzes were based on the International Journal on Media Management publications. The meta-study included a sample of 25 articles (out of 61 articles between 2013 and 2017). The analysis dimensions were: relationship with strategic management; goals and type of company. As results, we highlight the predominance $(72 \%)$ of studies involving decisions about business models and forms of financing. The studies portray different actors in this industry, such as traditional vehicles, media aggregators, newspapers, video platforms and news. As a contribution, this research advances in the literature on media management through the systematization of recent academic inquiries about strategic decisions, presenting categories of analysis for researchers and practitioners in journalism, communication and administration.

Keywords: Media business. Strategic decisions. Strategic management.

\section{Introdução}

A indústria jornalística com grandes empresas centralizadoras, verticais e hierarquizadas, de distribuição e consumo massivos, baseada nas plataformas 
de texto impresso, televisão e rádio, está enfrentando um processo de mudança sem precedentes (Anderson, Bell e Shirky, 2013).

A liberdade de consumo de informação trazida pelas novas tecnologias de comunicação transforma o tradicional conceito de gatekeeper (o guardião das informações) dosveículos demídia.Ojornal,comsuaagendadetemaspertinentes, está sendo pulverizado em diversas formas de se informar: empreendimentos independentes, blogs pessoais, canais de vídeo, podcasts, redes sociais e serviços de mensagens. Além disso, a digitalização da informação democratizou seu acesso, reduzindo-se a necessidade de um intermediador da imprensa.

Essa revolução na produção, distribuição e consumo de notícias abalou o modelo de negócios das indústrias informativas, principalmente na adesão de clientes e no volume de receitas financeiras. Por isso, o esforço atual do setor é criar novas organizações informativas, com novos modelos de negócio, de valor e de lucro. Não à toa, pesquisadores de comunicação estão se debruçando sobre conceitos de administração - e vice-versa. Pesquisadores multidisciplinares (Sanchez, 2017) refletem sobre as mudanças irreversíveis do setor e os desafios para manter as empresas informativas abertas e operantes.

Nesta etapa turbulenta da indústria de mídia, novos modelos de negócio são testados, novos arranjos são estabelecidos na cadeia de valor, empresas tradicionalmente voltadas para o universo off-line estabelecem transições, mais ou menos abruptas, para a lógica digital; novos players já nascem digitais e independentes das empresas tradicionais de mídia (legacy companies), os chamados nativos digitais. Movimentos e mudanças são parte ativa desta indústria, catalisados por decisões de natureza estratégica. Decisões estas para a sobrevivência, manutenção ou exploração de novos caminhos - tanto na forma de fazer negócios, na priorização de segmentos, na maneira de lidar com audiência existente ou latente, na estrutura organizacional que envolve rápidas adaptações, como também nos novos arranjos entre os elos da cadeia de valor pós-industrial.

Com base no cenário exposto, este estudo visa mapear as principais variáveis (internas/externas) e decisões na gestão estratégica de negócios de mídia para lidar com e antecipar problemas, bem como prospectar oportunidades dentro do atual ambiente de negócios na indústria de mídia. Para tanto, será realizado um meta-estudo do periódico International Journal on Media Management, analisando-se as publicações realizadas entre 2013 e 2017. Decisões estratégicas

Decisões fazem parte do dia a dia das pessoas e das organizações. Decidir é uma tentativa de criação de futuro, pois o futuro é, em parte, consequência das escolhas presentes. De forma ampla, decisões são importantes, pois 
moldam o futuro de uma pessoa, empresa ou país. Decisões definem a forma como queremos viver, a forma como as empresas querem operar e se posicionar frente à concorrência. Decisões ajudam na pavimentação de caminhos futuros para pessoas e organizações.

Decisão é um comprometimento específico para a ação, implica em uma escolha distinta e identificável, com recursos destinados à obtenção de resultados (Mintzberg e outros, 1976). De forma similar, Howard e Abbas (2015, p. 8), definem decisão como "uma escolha entre duas ou mais alternativas que envolve o comprometimento de recursos".

Neste sentido, os autores destacam que não basta o compromisso mental ou apenas a intenção para caracterizar uma decisão. De outra forma, o momento da decisão é aquele no qual mudar o curso de uma ação já estabelecida custa alguma coisa - tempo, recursos monetários, pessoas envolvidas, entre outros recursos que, por definição, são elementos escassos e são restrições das ações.

O processo decisório pode ser estruturado pela adoção de distintas etapas, tais como framing, definição de objetivos, geração de alternativas, análise de incertezas e trade-offs, avaliação das alternativas e compromisso para a ação (Clemen, 1995; Hammond e outros, 2004). Processos decisórios mais estruturados ou menos estruturados demandam comprometimento de recursos para uma dada alternativa, com o balanceamento de trade-offs entre opções com distintos graus de conflito, visto que os recursos humanos, financeiros e físicos, são limitados dentro de uma organização.

As decisões organizacionais podem ser de cunho operacional, tático ou estratégico.

Uma decisão estratégica pode ser caracterizada como não rotineira, feita por altos executivos de uma organização e que pode afetar de forma crítica a saúde e sobrevivência organizacional (Eisenhardt e Zbaracki, 1992). Possuem, em geral, alta complexidade analítica e organizacional (Parnell e outros, 2013).

Uma decisão é complexa, do ponto de vista analítico, se possui muitas variáveis envolvidas na modelagem do problema decisório; acentuada dinâmica temporal, em que o resultado de uma decisão influencia decisões posteriores, ou mesmo quando incertezas ocorrem em distintos momentos da decisão; muita incerteza na estimativa das informações, nos cenários e consequências previstas bem como múltiplos critérios para o julgamento das alternativas, sejam eles conflitantes ou inter-relacionados.

Já do ponto de vista organizacional, a decisão é complexa se possui muitos atores envolvidos; muito conflito entre os stakeholders durante $\mathrm{o}$ processo decisório; múltiplos interesses e motivações envolvendo a decisão e suas potenciais consequências; muita assimetria quanto ao poder exercido 
pelos diferentes integrantes da equipe de decisão; enquadramentos e modelos mentais iniciais muito divergentes para se lidar com a decisão; personalidades e competências heterogêneas da equipe responsável pela decisão, culminando em um processo complexo para a obtenção de consenso e análise decisória.

Escolhas, decisões, incertezas, características dos gestores, estabilidade versus turbulência externa, trade-offs qualitativos e quantitativos entre alternativas, política versus racionalidade, processo versus conteúdo, entre outros ingredientes, caracterizam a natureza multidimensional das decisões estratégicas.

\section{Gestão de negócios de mídia}

A Figura 1 ilustra o ciclo de vida da indústria de jornais, parte integrante da indústria de mídia. O ponto de interrogação colocado no século XXI apresenta a necessidade de mudanças na operação e nos modelos de negócios das empresas situadas na indústria de mídia, com a imposição de criação de novos vetores de crescimento.

\section{Figura 1 - Ciclo de vida da indústria de jornais}

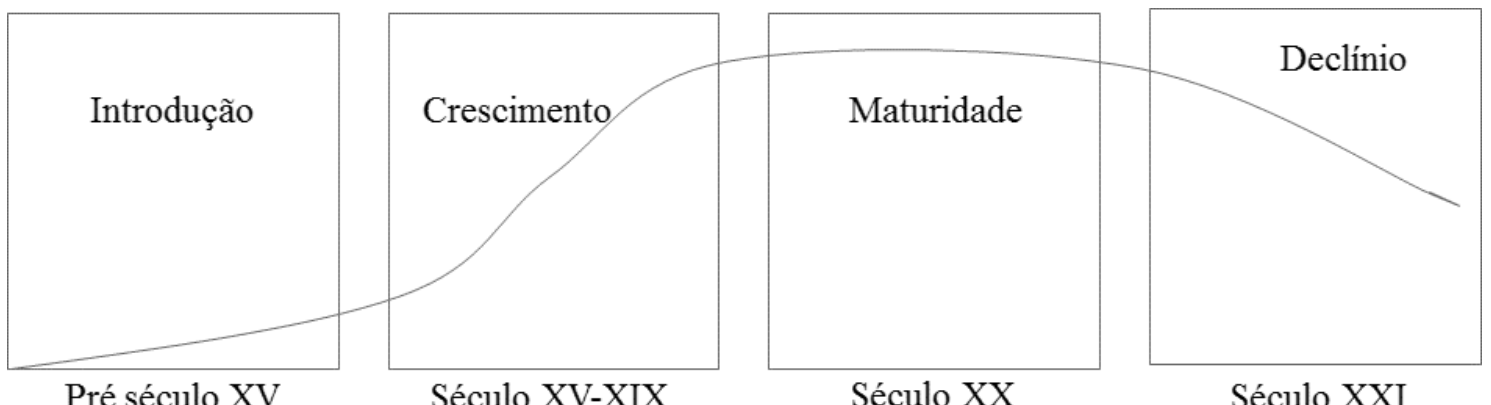

Fonte: Picard (2008, p. 715)

Picard (2008) demonstra a redução consistente da correlação, ao longo das últimas décadas, entre receitas dos veículos com propaganda e o produto interno bruto. A redução contínua deste importante pilar de receitas coloca pressão sobre os modelos de negócio correntes.

O passado estável, de altos crescimentos, é um passivo que dificulta o processo de renovação estratégica das empresas tradicionais de mídia. Modelos de negócio estáveis geraram histórias corporativas, consolidaram modelos mentais dos executivos da área, criaram competências específicas que dificultam adaptações rápidas e, cada vez mais, necessárias pela indústria de mídia (Picard, 2004). Ambientes repletos de mudanças, turbulências e 
instabilidades geram incertezas mercadológicas, financeiras e operacionais que demandam movimentos rápidos.

No Quadro 1, Albarran, ex-editor do International Journal on Media Management (IJMM), apresenta a evolução da gestão de negócios de mídia nas últimas décadas. Percebe-se o movimento acelerado das novas tecnologias na forma de atuação, na fragmentação da audiência, no surgimento de novos players na indústria de mídia, na renovação estratégica de negócios tradicionais para o caminho digital, nas novas experiências de criação de ofertas, mecanismos de funding e monetização.

\section{Quadro 1 - Marcos temporais sobre negócios de mídia}

\begin{tabular}{|l|l|}
\hline Década & \multicolumn{1}{c|}{ Marco } \\
\hline 1940 & $\begin{array}{l}\text { Primeiros livros com tópicos sobre gestão de negócios de mídia. Desenvolvimen- } \\
\text { to mais acelerado da mídia após a Segunda Guerra Mundial. }\end{array}$ \\
\hline 1950 & $\begin{array}{l}\text { Televisão emerge como meio massivo de comunicação. Aparecem pesquisas aca- } \\
\text { dêmicas sobre gestão de jornais. }\end{array}$ \\
\hline 1960 & $\begin{array}{l}\text { Satélites facilitam comunicação global. Televisão se torna o meio de comunica- } \\
\text { ção dominante e pesquisas seguem esta mudança. }\end{array}$ \\
\hline 1970 & $\begin{array}{l}\text { Desenvolvimento de transmissão via cabo/satélite. A circulação dos jornais co- } \\
\text { meça seu declínio. Aceleração da adoção de novas tecnologias com os equipa- } \\
\text { mentos de gravação em vídeo. }\end{array}$ \\
\hline 1980 & $\begin{array}{l}\text { Internet emerge como potencial meio de comunicação em massa, tendo o e-mail } \\
\text { como uma de suas aplicações iniciais. Dominância de redes televisivas. Primeiros } \\
\text { periódicos dedicados à análise da gestão e a dimensão econômica de negócios } \\
\text { de mídia. }\end{array}$ \\
\hline 2000 & $\begin{array}{l}\text { Novas tecnologias e sistemas de entrega de informaç̃̃es geram fragmentação } \\
\text { das audiências. Pesquisas acadêmicas sobre estes novos tipos de mídia flores- } \\
\text { cem. Acontece a primeira conferência mundial sobre economia da mídia, com } \\
\text { encontros bienais. }\end{array}$ \\
\hline 2010 & $\begin{array}{l}\text { O corpo editorial do Journal of Media Economics e o International Journal on Media } \\
\text { Management apresenta pesquisadores com alta diversidade e representatividade } \\
\text { mundial. }\end{array}$ \\
\hline $\begin{array}{l}\text { Explosão da propaganda em mídias sociais dentro de uma arena de mídia di- } \\
\text { versificada e fragmentada. Maior ênfase acadêmica em pesquisas relacionadas a } \\
\text { novas tecnologias de mídia do que pesquisa voltada à mídia "tradicional" }\end{array}$ \\
\hline
\end{tabular}

Fonte: Adaptado de Albarran (2014, p. 1.036)

$\mathrm{Na}$ indústria de mídia, Mierzjewska e Hollifiel (2006) analisaram as publicações, entre os anos 1998 e 2003, dos periódicos International Journal on Media Management e Journal of Media Economics. Como parte da análise verificaram que 44\% dos 309 artigos tinham como baseTeorias da Administração, 33\% Teorias Econômicas, 17\% Ensaios e 5\% Teorias da Comunicação. Tecendo 
considerações sobre este estudo, Albarran (2014) ressalta a ausência de teorias específicas da área de Gestão de Negócios de Mídia, ou seja, predomina o uso modelos e bases teóricas da administração e da economia, mesmo que as particularidades da indústria de mídia sejam consideradas nas pesquisas da área.

Dentre as Teorias da Administração usadas nos estudos sobre gestão de negócios de mídia, Mierzjewska e Hollifiel (2006) destacam, conforme Tabela 1, o uso de teorias sobre gestão estratégica (54\% dos 136 artigos baseados em teorias da administração).

Tabela 1 - Distribuição das abordagens em pesquisas sobre gestão de mídia

\begin{tabular}{|l|c|}
\hline Abordagem em Pesquisas sobre Gestão de Mídia & $\begin{array}{c}\text { Frequência de ocorrência } \\
\text { (total de 136 artigos) }\end{array}$ \\
\hline Teorias sobre gestão estratégica & $\mathbf{5 4 \%}$ \\
\hline Teorias sobre tecnologia, inovação, e criatividade & $21 \%$ \\
\hline Teorias sobre contingência e eficiência & $9 \%$ \\
\hline Teorias sobre consumo e comportamento da audiência & $12 \%$ \\
\hline Abordagens sobre economia política & $5 \%$ \\
\hline Teorias sobre cultura organizacional & $3 \%$ \\
\hline
\end{tabular}

Fonte: Adaptado de Mierzjewska e Hollifiel (2006, p. 41).

Mierzjewska e Hollifiel (2006) destacam a visão baseada em recursos (RBV) e a visão baseada na indústria como estruturas teóricas para a maioria dos estudos sobre gestão estratégica de negócios de mídia.

Após um trabalho de ampla revisão em um relevante periódico sobre estratégia, Nag, Hambrick e Chen (2007, p. 942) definem que a administração estratégica compreende as principais iniciativas empresariais tomadas pelos executivos em nome dos proprietários, envolvendo a utilização de recursos para aumentar o desempenho das empresas em seus ambientes competitivos.

A visão baseada em recursos considera a articulação dos recursos organizacionais como fonte de vantagem competitiva, pela criação dinâmica de competências centrais para atendimento das principais estratégias organizacionais (Barney, 1991).

Assim, não bastam apenas recursos, tais como máquinas, equipamentos, pessoas e tecnologias (tangíveis), bem como habilidades, imagem de marca, reputação, conhecimentos e procedimentos (intangíveis) para criação de barreiras competitivas. Recursos são necessários, mas não suficientes. Na lógica RBV, recursos devem ser gerenciados e integrados para a formação de capacidades organizacionais; algumas capacidades, por outro lado, podem ser integradas para a geração de competências. Desta forma, as competências 
centrais de uma organização ditam sua forma de agir e competir em seu mercado de atuação.

Na visão baseada na indústria, a empresa deve ser capaz de criar diferenciais que lhe garantam um poder de barganha superior perante os clientes e fornecedores, que lhe permita se posicionar melhor do que os concorrentes e criar barreiras contra a entrada de novos concorrentes e produtos substitutos (Porter, 1985). Nesta linha de análise, o ambiente externo possui grande poder sobre o potencial de lucratividade de uma dada indústria.

Embora a visão baseada em recursos privilegie o ambiente interno e considere os recursos organizacionais como fonte de vantagem competitiva, a empresa precisa também considerar o ambiente externo, seja para se adaptar evitando ameaças e aproveitando oportunidades, seja para modificá-lo criando novas estruturas de relações de troca. Existe um fluxo contínuo de trocas e retroalimentação entre o ambiente organizacional e o ambiente externo para a dinâmica operacional e competitiva de um empreendimento.

A busca por vantagens competitivas sustentáveis pode ser afetada pela estrutura de uma indústria, pela escolha dos gestores sobre modelos de atuação, pela estruturação e operação dos negócios, por formas de financiamento e investimento, bemcomo porrelacionamentoscom distintoselosdacadeia devalor.

Para atendimento do objetivo desta pesquisa, pretende-se agrupar, em categorias de análise, os estudos envolvendo decisões estratégicas na indústria de mídia.

\section{Abordagem metodológica}

Nota-se, pelo estudo de Mierzjewska e Hollifiel (2006), a predominância do uso de teorias sobre gestão estratégica como lente administrativa para investigações sobre gestão de negócios de mídia.

Esta pesquisa se caracteriza como um meta-estudo qualitativo, considerando-se variáveis e decisões para a gestão estratégica de negócios de mídia, entre 2013 e 2017, no periódico International Journal on Media Management (IJMM). Um meta-estudo procura sintetizar contribuições específicas de pesquisas em conclusões mais gerais, em padrões de descobertas e de análises.

O recorte temporal para este artigo se justifica pelo grau acelerado de mudanças dentro da indústria de mídia e pela natureza analítica proposta método de pesquisa. Desta forma, buscou-se investigar o foco acadêmico estabelecido nos últimos cinco anos, período de grande turbulência, transformações, ameaças e oportunidades na indústria de mídia (Sanchez, 2017). 
O periódico IJMM, conforme Mierzjewska e Hollifiel (2006), é relevante para pesquisas sobre negócios de mídia, tendo sua primeira edição em 1999. Possui como escopo editorial o acolhimento de conteúdo interdisciplinar envolvendo mídia, estratégia, finanças, operações, marketing, entre outros.

Após leitura do texto completo dos 61 artigos inseridos no período proposto de análise, 25 foram selecionados para a realização do meta-estudo. Estabeleceu-se como critério para inclusão do artigo o grau de aderência de suas contribuições teóricas ou empíricas para a gestão e decisões estratégicas em negócios de mídia, conforme fundamentação teórica desenvolvida nas seções anteriores.

Cada pesquisador codificou os artigos como de alta ou baixa aderência ao critério de seleção definido. Em uma segunda etapa, verificou-se a similaridade dos artigos selecionados entre os pesquisadores e julgamento conjunto de eventuais diferenças (apenas dois artigos foram descartados da análise por falta de consenso entre os pesquisadores). Desta forma, artigos sobre audiência, consumo de mídia, difusão de inovações, aspectos operacionais e gestão de marca não foram objeto do presente meta-estudo.

Como primeiro procedimento exploratório, foi desenvolvida uma nuvem de palavras a partir dos abstracts dos artigos selecionados, conforme Figura 2. A nuvem foi criada com o software livre Iramuteq, usando-se como critério as 30 palavras com maior frequência de ocorrência.

\section{Figura 2 - Nuvem de palavras do meta estudo}

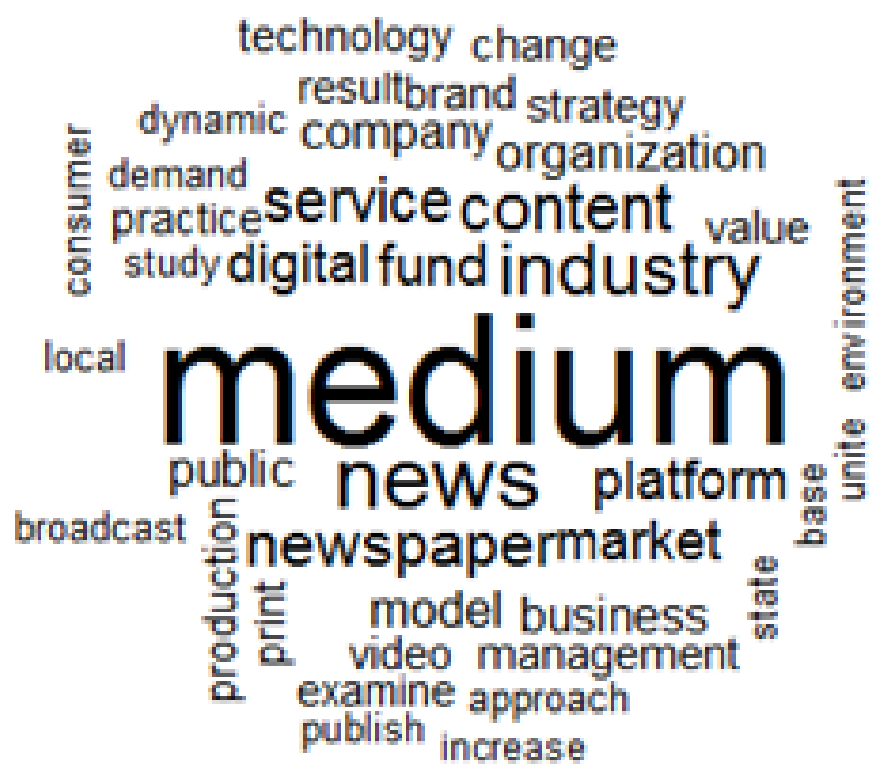

Fonte: Elaborado pelos autores (2017) 
Optou-se pela lematização para a utilização de dicionário reduzido no processamento das palavras (Iramuteq, 2017). Assim, por exemplo, as palavras strategy e strategies foram automaticamente agrupadas como strategy, bem derivações de media como medium.

Nota-se grande representatividade de ocorrência da palavra mídia e notícias, fato esperado pela natureza do periódico pesquisado. Além disso, figuram como representativas as palavras:modelo, negócios, indústria, conteúdo, digital, financiamento, produção, demanda, consumidor, organização, mudança, estratégia, resultado, tecnologia, gestão, mudança e marca. Mesmo com o caráter exploratório de uma nuvem de palavras, percebem-se terminologias híbridas envolvendo mídia e gestão no corpus pesquisado.

Com base na nuvem de palavras e na análise de conteúdo dos artigos selecionados, cada autor separou os estudos por afinidade temática. Novamente, divergências de categorização foram discutidas pelos autores e, neste caso, apresentadas a uma pesquisadora externa para validação, neutra no processo, doutora em Administração de Empresas pela Faculdade de Economia, Administração e Contabilidade da Universidade de São Paulo e integrante de um programa stricto sensu avaliado como nota cinco pela Coordenação de Aperfeiçoamento de Pessoal de Nível Superior (Capes).

O processo completo, desde a seleção da amostra de 25 artigos (no universo de 61 artigos entre 2013 e 2017), até a categorização dos estudos por afinidade temática, visa aumentar a confiabilidade e eventual replicação da pesquisa.

As quatro categorias atribuídas foram ordenadas pela maior frequência de ocorrência dentro da amostra pesquisada, sendo elas: a) modelos de negócio, b) formas de financiamento (funding), c) renovação estratégica e d) investimentos.

\section{Resultados e Discussão}

Os artigos selecionados foram avaliados no meta-estudo quanto à sua relação com a gestão estratégica (variáveis e/ou decisões), tipo de empresa de mídia e objetivos de pesquisa. Segue detalhamento e discussão sobre cada categoria.

a) Modelos de negócio:

O tema modelo de negócios, na amostra pesquisada, trata de diferenças de modelos e gestão entre negócios analógicos, digitais e híbridos, formas de relacionamento entre a oferta e a demanda (supply e demand side) para entrega de proposta de valor, plataformas para negócios, modelos ancorados na gratuidade e o impacto de novos elos na cadeia de valor da indústria informativa. 
Esta categoria, conforme Quadro 2, foi a mais representativa dentro do meta-estudo, com $40 \%$ das publicações no período.

\section{Quadro 2 - Categoria - Modelos de negócio}

\begin{tabular}{|c|c|c|}
\hline Artigo & Síntese & $\begin{array}{l}\text { Tipo de Empresa de } \\
\text { Mídia }\end{array}$ \\
\hline $\begin{array}{l}\text { Schultz e Jones } \\
(2017)\end{array}$ & $\begin{array}{l}\text { Análise de fatores relevantes para o sucesso de } \\
\text { dois empreendimentos de mídia local, um em } \\
\text { zona rural (Wyoming) e outro urbano (Harlem) }\end{array}$ & $\begin{array}{l}\text { Portal online de notícias } \\
\text { locais, em zona rural e } \\
\text { um jornal físico local ur- } \\
\text { bano, ambos nos Estado } \\
\text { Unidos }\end{array}$ \\
\hline $\begin{array}{l}\text { Arrese e Kaufmann } \\
(2016)\end{array}$ & $\begin{array}{l}\text { Diferenças entre empresas tradicionais de mídia } \\
\text { e nativos digitais quando ambos operam no am- } \\
\text { biente digital }\end{array}$ & $\begin{array}{l}\text { Media legacies e nativos } \\
\text { digitais na Espanha }\end{array}$ \\
\hline $\begin{array}{l}\text { Poutanen, Luoma- } \\
\text {-Aho e Suhanko } \\
\text { (2016) }\end{array}$ & $\begin{array}{l}\text { Análise de quatro dilemas (trade-offs) na função } \\
\text { híbrida exercida pelos editores, que mistura jor- } \\
\text { nalismo e preocupações com a gestão do negó- } \\
\text { cio }\end{array}$ & $\begin{array}{l}\text { Revistas sobre estilo de } \\
\text { vida e jornais na Finlândia }\end{array}$ \\
\hline Lee e Chyi (2015) & $\begin{array}{l}\text { Agregadores como catalisadores de oferta e de- } \\
\text { manda }\end{array}$ & $\begin{array}{l}\text { Agregadores online de } \\
\text { notícia }\end{array}$ \\
\hline Gimpel (2015) & $\begin{array}{l}\text { Teoria da plataforma como arranjo de negócios e } \\
\text { decisões de diferentes atores no ecossistema das } \\
\text { plataformas de vídeos }\end{array}$ & Plataformas de vídeos \\
\hline Meyer e Tang (2015) & $\begin{array}{l}\text { Uso do Twitter como alavanca para o negócio } \\
\text { jornalístico }\end{array}$ & $\begin{array}{l}\text { Canais televisivos de notí- } \\
\text { cias locais e jornais locais } \\
\text { nos Estados Unidos }\end{array}$ \\
\hline $\begin{array}{l}\text { Kehoe e Mateer } \\
(2015)\end{array}$ & $\begin{array}{l}\text { Modelos alternativos de distribuição (orientação } \\
\text { para oferta versus demanda) }\end{array}$ & $\begin{array}{l}\text { Distribuidores indepen- } \\
\text { dentes de filmes no Reino } \\
\text { Unido }\end{array}$ \\
\hline $\begin{array}{l}\text { Goyanes e Dür- } \\
\text { renberg (2014) }\end{array}$ & $\begin{array}{l}\text { Distribuição digital e estratégias de adoção de } \\
\text { conteúdo pago (taxonomia para categorização } \\
\text { em ambientes multiplataforma) }\end{array}$ & Jornais espanhóis \\
\hline Hess (2014) & $\begin{array}{l}\text { Discussão sobre o foco na publicação ou trans- } \\
\text { missão versus na abordagem de plataforma de } \\
\text { notícias }\end{array}$ & $\begin{array}{l}\text { Não aplicável } \\
\text { (ensaio teórico) }\end{array}$ \\
\hline Nee (2013) & $\begin{array}{l}\text { Diferenças e similaridades entre a gestão de ne- } \\
\text { gócios nativos digitais e negócios tradicionais }\end{array}$ & $\begin{array}{l}\text { Negócios digitais nos } \\
\text { Estados Unidos }\end{array}$ \\
\hline
\end{tabular}

Fonte: Elaborado pelos autores (2017)

Nee (2013) avançou na pesquisa sobre os negócios de mídia nativos digitais, ou seja, negócios independentes e com vocação para o universo digital. O autor analisou quatro dimensões: a) se a plataforma nativa digital trouxe impacto diferente na forma de cumprir sua missão jornalística, comparandose com negócios tradicionais; b) percepção sobre aspectos competitivos e colaborativos com empresas tradicionais; c) como as empresas nativas digitais pretendem alcançar sustentabilidade financeira em suas operações e d) como os gestores das empresas nativas aproveitam as competências adquiridas, 
eventualmente, em sua trajetória prévia em negócios tradicionais para alavancar o potencial do uso de novas tecnologias.

O ensaio teórico produzido por Hess (2014) traz comparações entre modelos de negócio com foco na publicação-transmissão versus modelos com abordagem de plataforma de notícias. $\mathrm{O}$ artigo traz comparações sobre as duas formas de atuação, como por exemplo, quanto à criação de valor (criação de conteúdo versus gestão de conteúdo); competências centrais da empresa de mídia (jornalísticas e artísticas versus tecnológicas); responsabilidade principal no tratamento de conteúdo (humanos versus máquinas); foco nas aplicações de tecnologia de informação (armazenamento e disponibilização de conteúdo versus filtro e geração de conteúdo por algoritmos).

Hess (2014) aponta empresas tradicionais de jornais, revistas, publicação de livros, emissoras de televisão e rádio como representantes do modelo publicação-transmissão e como players com abordagem do tipo de plataforma: motores de busca, redes sociais, portais de opinião, plataformas de contato e marketplaces. Neste contexto, de mudanças na cadeia de valor da indústria, o autor sugere a seguinte definição para empresas de mídia: "empresas de mídia como organizadoras da comunicação pública baseada em mídia, podendo operar como provedoras de conteúdo, como operadores de plataforma ou em formatos híbridos"(Hess, 2014, p.6). Esta definição tem o potencial de redirecionar a análise de concorrentes e parceiros, redefinir ameaças e oportunidades e lançar luz sobre competências necessárias para a geração de negócios prósperos, alcançadas dentro dos próprios recursos do empreendimento ou adquiridas via aquisições, fusões ou compra de participações acionárias em startups tecnológicas.

Um vetor de mudança possibilita diferentes escolhas para gestores e empresas, como o caso da digitalização do consumo de filmes. Kehoe e Mateer (2015), discutem modelos alternativos de negócio, orientados para a oferta (content-driven) versus orientados para a demanda (consumer-driven) para melhor atendimento dos consumidores de filmes independentes. A análise possui como estrutura teórica o modelo da cadeia de valor proposto por Porter (1985). O estudo de caso múltiplo, com duas produtoras independentes de filmes no Reino Unido, aponta que nenhum modelo de distribuição multiplataforma tomará totalmente o lugar da rígida cadeia de valor estabelecida por empresas tradicionais, ao menos no curto prazo, mas modelos alternativos, de base tecnológica como o Netflix, podem alterar o equilíbrio de forças no longo prazo, seja pela diversidade, produção própria, customização, uso de inteligência artificial e atendimento eficiente de audiência ávida pelo conveniência do consumo de filmes em múltiplas telas. 
Nesta categoria, encontram-se formas de captura e entrega de valor na coordenação e integração de esforços entre a geração de demanda e adequação de estrutura organizacional para suportá-la adequadamente.

b) Formas de financiamento (funding):

As organizações precisam de mecanismos sustentáveis de financiamento de suas atividades para exploração comercial do negócio e manutenção de atividades jornalísticas que prezem pela qualidade editorial.

A categoria formas de financiamento trata de diferentes alternativas de funding em empresas variadas na indústria de mídia como em produtoras de filmes, jornais, animações, emissoras e videogames. Crowdfunding, taxa de licenciamento e compra de parte acionária de startups são alguns formatos explorados na amostra.

Importante destacar que a dimensão monetização e formas de sustentação financeira fazem parte do desenho de um modelo de negócio, mas optou-se pela caracterização separada desta categoria por dois motivos: a) quantidade de artigos sobre esta temática dentro do IJMM no período pesquisado (2013-2017), principalmente na segunda edição de 2017, dedicada ao tema; b) relevância da discussão mercadológico-financeira de mecanismos de financiamento para sobrevivência e exploração de oportunidades em ambiente de turbulência e incertezas vivenciado pela indústria de mídia.

Esta categoria, conforme Quadro 3, foi a segunda com maior ocorrência dentro do meta-estudo, representando $32 \%$ das publicações no período. 
Quadro 3 - Categoria - Formas de financiamento (funding)

\begin{tabular}{|l|l|c|}
\hline \multicolumn{1}{|c|}{ Artigo } & \multicolumn{1}{|c|}{ Síntese } & \multicolumn{1}{c|}{$\begin{array}{c}\text { Tipo de Empresa de } \\
\text { Mídia }\end{array}$} \\
\hline Cha (2017) & $\begin{array}{l}\text { Análise sobre os fatores que ampliam a possibi- } \\
\text { lidade de sucesso de iniciativas de crowdfunding } \\
\text { para projetos de videogames }\end{array}$ & $\begin{array}{c}\text { Plataforma de crowdfun- } \\
\text { ding Kickstarter }\end{array}$ \\
\hline Bonini e Pais (2017) & $\begin{array}{l}\text { Modelo alternativo de financiamento de serviços } \\
\text { públicos de mídia (PSM) }\end{array}$ & $\begin{array}{c}\text { Mídia de serviço público } \\
\text { na Itália }\end{array}$ \\
\hline Ladson e Lee (2017) & $\begin{array}{l}\text { Fatores que contribuem para o sucesso financei- } \\
\text { ro da Byline. }\end{array}$ & $\begin{array}{l}\text { Plataforma internacional } \\
\text { de crowdfunding jornalís- } \\
\text { tico: Byline }\end{array}$ \\
\hline $\begin{array}{l}\text { Papadimitriou } \\
\text { (2017) }\end{array}$ & $\begin{array}{l}\text { Potencial do uso de crowdfunding para financia- } \\
\text { mento de filmes de baixo orçamento }\end{array}$ & $\begin{array}{c}\text { Indústria de filmes na } \\
\text { Grécia }\end{array}$ \\
\hline Potter (2017) & $\begin{array}{l}\text { Impacto de mudanças na cadeia de valor do se- } \\
\text { tor televisivo na produção de conteúdo exclusivo } \\
\text { para o público infantil. }\end{array}$ & $\begin{array}{c}\text { Produção televisiva para } \\
\text { crianças no Reino Unido e } \\
\text { na Austrália }\end{array}$ \\
\hline $\begin{array}{l}\text { Loriguillo-López } \\
\text { (2017) }\end{array}$ & $\begin{array}{l}\text { Explora o crowdfunding como potencial alterna- } \\
\text { tiva para o financiamento de animações japone- } \\
\text { sas. }\end{array}$ & $\begin{array}{c}\text { Produção de animações } \\
\text { no Japão }\end{array}$ \\
\hline Tennant (2014) & $\begin{array}{l}\text { Modelos gratuitos de jornais em empresas tradi- } \\
\text { cionais de mídia impressa }\end{array}$ & $\begin{array}{c}\text { Jornais nos Estados Uni- } \\
\text { dos }\end{array}$ \\
\hline Lowe e Berg (2013) & $\begin{array}{l}\text { Análise do financiamento de serviços públicos } \\
\text { de mídia }\end{array}$ & $\begin{array}{c}\text { Empresas de radiodifusão } \\
\text { na Europa }\end{array}$ \\
\hline Fonte:Elabramo
\end{tabular}

Fonte: Elaborado pelos autores (2017)

Em estudo quantitativo, Cha (2017) analisou o impacto de seis fatores no potencial sucesso de financiamento de projetos para vídeo games por meio da plataforma de crowdfunding Kickstarter, sendo a medida de sucesso (variável dependente) a obtenção, ou não, do recurso solicitado. Para utilização de regressão logística, usou as seguintes variáveis independentes: localização, tamanho da equipe, tamanho do mercado, capital social, retrospecto educacional dos empreendedores e experiência destes na indústria de games. As variáveis independentes são derivadas da teoria da riqueza de mídia e da teoria da sinalização. O estudo analisou 447 campanhas de crowdfunding realizadas entre 2011 e 2015, com metas individuais de arrecadação entre US\$ 100 mil e US\$ 1 milhão.

Ladson e Lee (2017) realizaram um estudo de caso para investigar os fatores que contribuem para o sucesso financeiro da Byline, plataforma específica para crowdfunding de iniciativas jornalísticas. Os autores estabelecem o sucesso de financiamento dos projetos e iniciativas da plataforma como proxy para o sucesso financeiro da própria plataforma, com racionais envolvendo a taxa média de arrecadação por projeto e o percentual destinado à Byline. O tipo de conteúdo, a localidade do autor e as opções de recompensa, configuram-se como variáveis preditoras no sucesso do crowdfunding em jornalismo. 
De formas diferentes, Loriguillo-López (2017) e Bonini e Pais (2017) analisam o impacto da participação da audiência no processo de ampliação e obtenção do financiamento. Loriguillo-López investiga o processo de financiamento coletivo para a produção de animações comerciais japonesas. Neste estudo, explora o crowdfunding como termômetro do potencial sucesso das produções em outros países devido à localidade dos doadores, auxiliando na demonstração da viabilidade do projeto para investidores institucionais. Bonini e Pais (2017), em um experimento conduzido pela internet, analisam a propensão da audiência em emissoras públicas italianas em pagar taxas de licenciamento maiores caso participassem de forma mais ativa na definição da grade de programação. Os autores constataram a ligação entre o desejo de colaborar e participar deste processo decisório e potencial aumento de contrapartida financeira via pagamento de taxa superior de licenciamento. Cabe ressaltar que o modelo europeu de Public Service Media (PSM) possui fração significativa de suas receitas decorrentes do recebimento de taxas de licenciamento de seus usuários (Lowe e Berg, 2013).

Em conjunto, os artigos enquadrados nesta categoria promovem discussões variadas sobre a participação e colaboração da audiência no processo de financiamento e a busca pela manutenção do jornalismo e produtos midiáticos de qualidade. Além disso, demonstram a diversidade das empresas de mídia inseridas nas pesquisas sobre media management (produção de videogames, filmes, jornalismo independente, emissoras públicas e produção de animações).

c) Renovação estratégica:

A categoria renovação estratégica, presente em 16\% das publicações do período analisado, envolve pesquisas sobre mudanças na operação, na estratégica mercadológica, no posicionamento competitivo ou na própria natureza do modelo de negócios. 
Quadro 4 - Categoria - Renovação estratégica

\begin{tabular}{|l|l|c|}
\hline \multicolumn{1}{|c|}{ Artigo } & \multicolumn{1}{|c|}{ Síntese } & \multicolumn{1}{c|}{ Tipo de Empresa de Mídia } \\
\hline $\begin{array}{l}\text { Horst e Moisander } \\
(2015)\end{array}$ & $\begin{array}{l}\text { Análise de paradoxos relacionados com ori- } \\
\text { gem na história da empresa e nas decisões da } \\
\text { equipe de gestão }\end{array}$ & $\begin{array}{l}\text { Grandes empresas europeias } \\
\text { tradicionais de mídia impres- } \\
\text { sa em transição para o digital }\end{array}$ \\
\hline $\begin{array}{l}\text { Järventie-Thesleff, } \\
\text { Moisander e Villi } \\
(2014)\end{array}$ & $\begin{array}{l}\text { Transição do meio impresso para um negócio } \\
\text { com características digitais }\end{array}$ & $\begin{array}{c}\text { Empresas de mídia no norte } \\
\text { europeu }\end{array}$ \\
\hline $\begin{array}{l}\text { Mierzejewska e Sha- } \\
\text { ver (2014) }\end{array}$ & $\begin{array}{l}\text { Direcionadores de mudanças no ecossistema } \\
\text { de mídia, gerando diferentes possibilidades } \\
\text { estratégicas }\end{array}$ & $\begin{array}{c}\text { Não aplicável } \\
\text { (ensaio teórico) }\end{array}$ \\
\hline $\begin{array}{l}\text { Maijanen e Jantu- } \\
\text { nen (2014) }\end{array}$ & $\begin{array}{l}\text { Transição e convivência entre o analógico e } \\
\text { o digital }\end{array}$ & $\begin{array}{l}\text { Empresa finlandesa de radio- } \\
\text { difusão }\end{array}$ \\
\hline
\end{tabular}

Fonte: Elaborado pelos autores (2017)

Como exemplo, Maijanen e Jantunen (2014) argumentam que a estabilidade e a mudança exercem tensões importantes para a definição e execução da estratégia organizacional. Os autores apontam para a natureza de forças centrípetas, ou seja, favoráveis ao processo de renovação estratégica e forças centrífugas, de manutenção do status quo; analisam o processo de renovação sob três dimensões interligadas: modelos mentais dos gestores, capacidades dinâmicas da organização e convivência entre diferentes áreas organizacionais na transição para um modelo mais digital. Utilizam-se da visão baseada em recursos como estrutura teórica de análise.

Järventie-Thesleff e outros (2014) argumentam que a gestão de negócios de mídia multiplataforma precisa de estratégias e práticas organizacionais ambidestras, ou seja, capazes de unir eficiência e inovação em seu modelo de negócios, possibilitando mudanças incrementais, que garantam melhorias pequenas em produtos e nas operações para entrega de maior valor a sua audiência e mudanças radicais para garantir a relevância do empreendimento frente às turbulências contextuais bem como aproveitar novas possibilidades associadas a cadeia de valor da indústria informativa e, eventualmente, mudar a forma de competição frente a seus rivais. A base da discussão concentrase no trade-off entre eficiência em curto prazo e inovações como motor para competitividade futura.

Os autores, por meio de estudo qualitativo, com dois estudos de caso em empresas nórdicas de mídia multiplataforma, apontam dificuldades na convivência entre modelos impressos e digitais pelos distintos recursos, competências, processos e métricas necessárias em cada iniciativa. Por isso, como principal insight do estudo, identificam a necessidade de uma gestão 
ambidestra, com design organizacional que persiga ganhos incrementais e radicais.

Mierzejewska e Shaver (2014), em ensaio teórico, trazem discussões sobre dez direcionadores de mudança na indústria de mídia, como a redefinição sobreo que é uma empresa de mídia, a fragmentação do consumo e audiência, o desafio do valuation de novos modelos de negócio digitais e o impacto econômico das tecnologias digitais para além do contexto das mídias tradicionais, afetando todo o ecossistema de notícias. Tais direcionadores impulsionam e condicionam, em maior ou menor grau, processos de renovação estratégica na indústria de mídia.

Nesta categoria, fica mais evidente a presença de estudos com enfoque teórico relacionado à visão baseada em recursos (VBR). Mierzejewska e Shaver (2014), em seu estudo sobre múltiplos direcionadores de mudança, trazem à luz impactos bidirecionais entre a VBR e a visão baseada na indústria, na qual condicionantes externos afetam o potencial de lucratividade de uma indústria e a capacidade de geração de vantagens competitivas.

d) Investimentos:

Esta categoria, representada por $12 \%$ da amostra, reflete diferentes decisões sobre investimentos, sejam eles destinados para expansão dos negócios (fusões e aquisições), aquisições para melhoria de competências organizacionais e uso capital de risco corporativo para compra de participação acionária (equity) de startups na cadeia de valor da indústria de mídia.

\section{Quadro 5 - Categoria - Investimentos}

\begin{tabular}{|l|l|c|}
\hline \multicolumn{1}{|c|}{ Artigo } & \multicolumn{1}{|c|}{ Síntese } & \multicolumn{1}{c|}{ Tipo de Empresa de Mídia } \\
\hline $\begin{array}{l}\text { Hasenpusche } \\
\text { Baumann (2017) }\end{array}$ & $\begin{array}{l}\text { Análise de três diferentes padrões para inves- } \\
\text { timentos corporativos de capital de risco em } \\
\text { startups }\end{array}$ & $\begin{array}{c}\text { Indústria de telecomunicação, } \\
\text { tecnologia da informação, mídia } \\
\text { e entretenimento (TIME industries) }\end{array}$ \\
\hline Solosk (2015) & $\begin{array}{l}\text { Checagem da influência de aquisições mal- } \\
\text { sucedidas na eventual alteração no quadro } \\
\text { de colaboradores da alta gestão das empre- } \\
\text { sas jornalísticas }\end{array}$ & $\begin{array}{l}\text { Companhias jornalísticas com } \\
\text { ações negociadas na bolsa de } \\
\text { valores (EUA) }\end{array}$ \\
\hline $\begin{array}{l}\text { Duchessi e } \\
\text { Biswas (2013) }\end{array}$ & $\begin{array}{l}\text { Análise de criação de valor via aquisição de } \\
\text { empresas de tecnologia de informação }\end{array}$ & $\begin{array}{c}\text { Empresas de publicação e im- } \\
\text { pressão nos EUA }\end{array}$ \\
\hline
\end{tabular}

Em estudo sobre investimento corporativo em capital de risco, Hasen pusche Baumann (2017) analisaram padrões de alocação de investimento por empresas tradicionais e de destaque na indústria de telecomunicações, tecnologia da informação, mídia e entretenimento. Como resultado de uma análise multivariada de conglomerados (cluster analysis), os autores identificaram 
três clusters, com empresas similares intragrupo e diferentes, estatisticamente, entre grupos. Dentre os clusters identificados, tipificados como perfil agressivo, atento e disperso de investimento, perceberam que empresas da indústria de mídia e entretenimento tinham maior representatividade no cluster "atento", ou seja, com investimento em startups com similaridade operacional aos seus negócios já estabelecidos.

Enquanto o perfil agressivo, dominado por empresas do setor de tecnologia de informação, busca ampliar suas competências via participação em startups de mídia. A maioria das empresas tradicionais de mídia faz compras acionárias reativas, revelando uma espécie de aversão tecnológica e passividade diante de turbulências no ambiente de negócios. Autores sinalizam para os perigos deste perfil, discutindo a renovação e criação de competências em mídia por empresas tradicionais da indústria de tecnologia de informação como ameaça presente e tendência futura.

Solosk (2015) examinou aquisições contínuas, e malsucedidas financeiramente entre o período de 2000 e 2012, checando a influência dos resultados conquistados em mudanças no quadro de colaboradores das equipes de alta gestão responsáveis por tais movimentos de mercado na indústria de mídia. Ele verificou baixa correlação estatística entre resultados negativos, oriundos de aquisições, e mudanças na equipe da alta cúpula de gestão, ou seja, no quadro executivo de companhias jornalísticas americanas com ações negociadas na bolsa de Nova lorque.

Nesta categoria, investimentos, os processos de fusões, aquisição e compra de participação acionária em startups buscam, entre outros pontos, conquista de recursos e competências como potencial fonte de vantagens competitivas. Decisões sobre investimentos, em nível corporativo, funcionam como alavancas estratégico-financeiras para operação de modelos de negócios estabelecidos ou até como ingredientes em processos de renovação estratégica para a sustentabilidade e exploração de novas oportunidades na cadeia de valor da indústria de mídia.

O meta-estudo complementa e avança no trabalho desenvolvido por Mierzjewska e Hollifiel (2006), pois desmembra o bloco Teorias sobre Gestão Estratégica (Tabela 1) em quatro categorias passíveis de análise: modelos de negócio (40\%), formas de financiamento (32\%), renovação estratégica (16\%) e investimentos (12\%). Além disso, demonstra o potencial, conforme explicitado por Albarran (2014), de combinação e adaptação de saberes do campo da Administração, com os campos da Comunicação e do Jornalismo para a produção de pesquisas relevantes sobre decisões e gestão estratégica de negócios de mídia. 
A Figura 3 apresenta modelo integrativo das categorias levantadas neste meta-estudo, revelando potenciais interações e possibilidades de pesquisas acadêmicas.

\section{Figura 3 - Modelo integrativo das categorias}

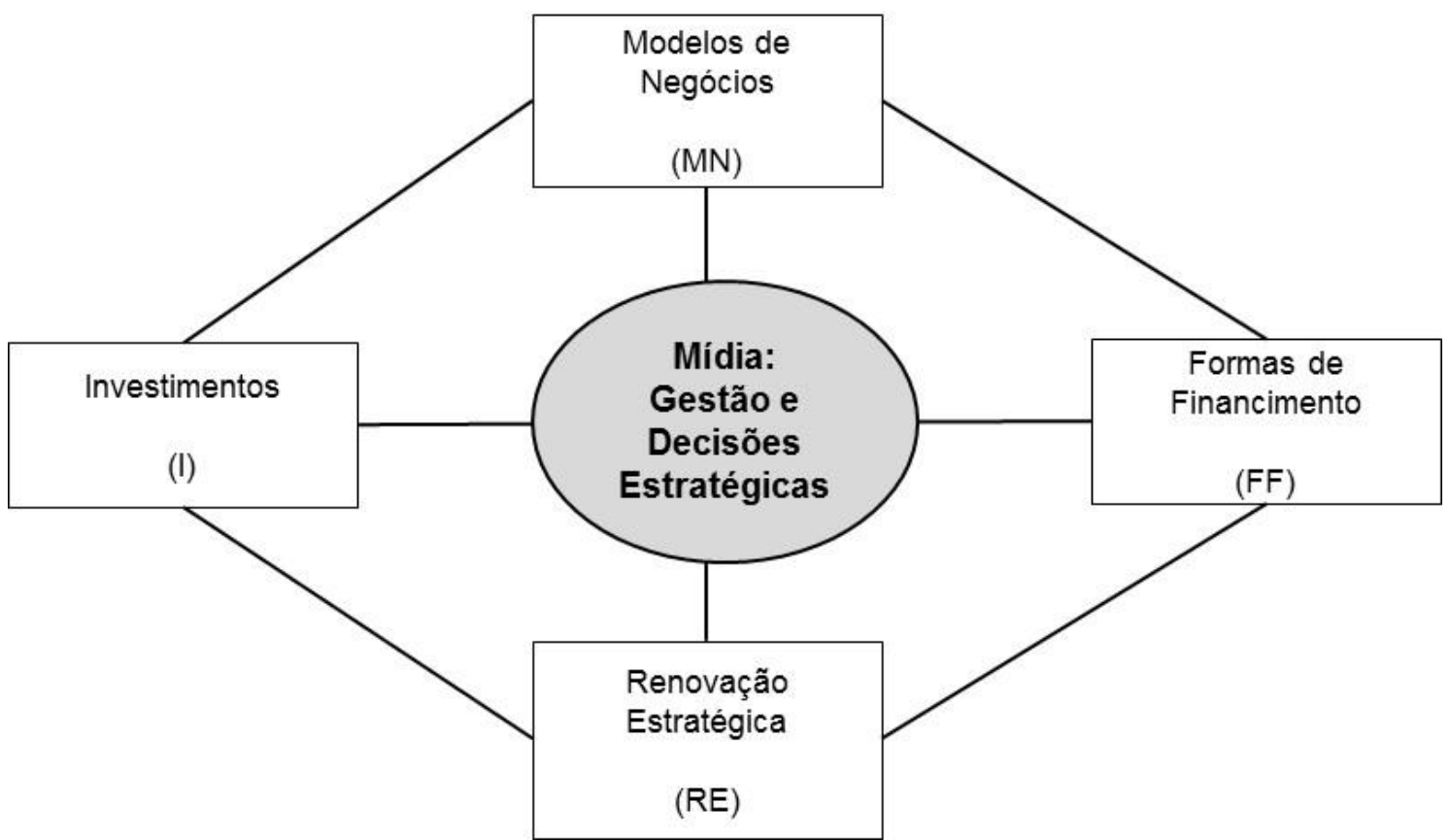

Fonte: Elaborada pelos autores (2017)

Como contribuição adicional, o meta-estudo revelou que as pesquisas explicitam poucas relações entre as categorias levantadas. A Figura 3 permite a visualização de tais relações, ampliando-se possibilidades futuras de pesquisa intra e entre categorias.

Exemplos de potenciais relações: a) Relação entre FF e I para obtenção de resultados superiores; b) Relação entre MN existentes e processos de renovação estratégica; c) Relação entre RE e necessidade de I para aquisição e transformação de competências organizacionais; d) Relação entre RE e novas $\mathrm{FF}$, trazendo novos potenciais de monetização nos processos de mudança estratégica; e) Relação entre MN e I para suportar e aumentar a eficiência do modelo de operação. A Figura destaca outras relações bidirecionais ou até mesmo multidirecionais (I-RE-MN-FF), como a necessidade de investimentos para a renovação estratégica de modelos de negócio tradicionais, com a geração de novas formas de financiamento na cadeia de valor da indústria de mídia. 


\section{Considerações finais}

O meta-estudo desenvolvido aponta para a diversidade de empresas de mídia em pesquisas envolvendo decisões estratégicas, tais como: veículos tradicionais de mídia impressa, agregadores de mídia, plataformas de vídeos e notícias, jornais locais e urbanos, produtoras de vídeos e games. Além disso, demonstra a participação de várias regiões nos estudos, como Estados Unidos, Espanha, Japão, Austrália, Reino Unido, Finlândia e outros países da Europa. Nota-se a ausência de estudos sobre negócios brasileiros na amostra pesquisada, demonstrando uma trilha de pesquisa fértil para pesquisadores nacionais envolvidos em estudos sobre as diversas facetas do media management.

Destacam-se estudos que apresentam e analisam decisões sobre modelos de negócio, formas de estruturação da oferta compatível com a geração de demanda desejada, impactos de novos elos da cadeia de valor da indústria informativa na modelagem de arquiteturas organizacionais compatíveis com os desafios e oportunidades impostas pelo ambiente de negócios.

Estudos sobre formas de financiamento (funding) também se destacam, abordando modelos de funding com graus variados na participação da audiência, seja na forma de contribuições voluntárias ou pelo desejo de participação nas decisões sobre conteúdo.

As categorias Renovação Estratégica e Investimento, em menor proporção, demonstram dilemas empresariais, trade-offs no processo decisório estratégico e formas de expansão via aquisição, fusão ou via capital de risco corporativo.

Como principais contribuições, este meta-estudo avança no processo de compreensão do objeto de pesquisa media management. Com finalidade exploratória, o modelo integrativo das categorias, introduzido na seção anterior, possibilita uma visão panorâmica sobre temas de interesse da comunidade acadêmica nacional e internacional. O modelo traz um mapa de navegação para novas pesquisas intra ou entre categorias. Novas relações de causa e efeito podem ser observadas com a adoção de uma abordagem sistêmica, ou seja, por meio de pesquisas empíricasfuturas queabordem múltiplas categorias simultaneamente.

Este estudo possui limitações quanto ao horizonte temporal de análise, embora capte e categorize temáticas recentes (últimos cinco anos) na área de media management. Além disso, recomenda-se a expansão do meta estudo em outros periódicos da área, com distintas perspectivas editoriais, como por exemplo o Journal of Media Economics.

Por fim, alerta-se que o momento atual de crise, downsizing de redações, reestruturação de modelos de negócio, fragmentação da audiência, velocidadee multiplicidade de canais na distribuição de notícias, abundância de informações e avanço de players tecnológicos na indústria de mídia é, ao mesmo tempo, uma 
avenida para novas oportunidades, tanto empresariais quanto acadêmicas. Pesquisas relevantes sobre media management, mais especificamente sobre decisões estratégicas em negócios de mídia, demandam olhares e saberes de pesquisadores oriundos de campos distintos de conhecimento, como o Jornalismo, a Comunicação, a Administração de Empresas e a Tecnologia da Informação.

\section{Referências}

ALBARRAN, A. B. Assessing the Field of Media Management and Economics Research: Looking Back, Looking Forward. Palabra Clave, v. 17, n. 4, p. 1025-1040, 2014.

ANDERSON, C. W.; BELL, E.; SHIRKY, C. Jornalismo pós-industrial: adaptação aos novos tempos. Revista de Jornalismo ESPM, v. 5, p. 30-89, abril-junho 2013.

ARRESE, A., KAUFMANN, J. Legacy and Native News Brands Online: Do they show different news consumption patterns? International Journal on Media Management, v. 18, n. 2, p. 75-97, 2016.

BARNEY, J. B. Firm resources and sustained competitive advantage. Journal of Management, v. 17, n. 1, p. 99-101, 1991.

BAUMANN, S.; HASENPUSCH, T. Strategic Media Venturing: Corporate Venture Capital Approaches of TIME Incumbents. International Journal on Media Management. v. 19, n. 1, p. 77-100, 2017.

BONINI, T.; PAIS, I. Hacking Public Service Media Funding: A Scenario for Rethinking the License Fee as a Form of Civic Crowdfunding. International Journal on Media Management, v. 19, n. 2, p. 123-143, 2017.

CHA, J. Crowdfunding for Video Games: Factors that Influence the Success of and Capital Pledged for Campaign. International Journal on Media Management, v. 19, n. 3, p. 240-259, 2017.

CLEMEN, R. T. Making Hard Decisions: an introduction to decision analysis. Duxbury: Second Edition, 1995.

DUCHESSI, P.; BISWAS, R. Value Creation in the Publishing Industry: The Impact of Acquiring IT Services Firms Between 2002 and 2007. International Journal on Media Management, v. 15, n. 4, p. 211-228, 2013.

EISENHARDT, K. M.; ZBARACKI, M. J. Strategic Decision Making. Strategic Management Journal, [S.I.], v. 13, [s .n.], p. 17-37, winter 1992.

GIMPEL, G. The Future of Video Platforms: key questions shaping the TV and video industry.International Journal on Media Management, v.17,n. 1, p.25-46, 2015. 
GOYANES, M.; DURRENBERG, C. A Taxonomy of Newspapers based on Multi-Platform and Paid Content Strategies: evidences from Spain. International Journal on Media Management, v. 16, n. 1, p. 27-45, 2014.

HAMMOND, J.S., KEENEY, R.L., RAIFFA, H. Decisões Inteligentes. Rio de Janeiro: Elsevier, 2004.

HESS, T. What is a Media Company? A reconceptualization for the online world. International Journal on Media Management. v. 16, n. 1, p. 3-8, 2014.

HORST, S., MOISANDER, J. Paradoxes of Strategic Renewal in Traditional Print-Oriented Media Firms. International Journal on Media Management, v. 17, n. 3, p. 157174, 2015.

HOWARD, R. A.; ABBAS, A. E. Foundations of Decision Analysis. New Jersey, Pearson, 2015.

IRAMUTEQ. Tutorial para uso do software de análise textual IRAMUTEQ. Disponível em: http://www.iramuteq.org/documentation/fichiers/tutoriel-en-portugais. Acesso em: 18 ago. 2017.

JÄRVENTIE-THESLEFF, R.; MOISANDER, J.; VILLI, M. The Strategic Challenge of Continuous Change in Multi-Platform Media Organizations: a strategy-aspractice perspective. International Journal on Media Management. v. 16, n. 3-4, p. 123-138, 2014.

KEHOE, K.; MATEER, J. The Impact of Digital Technology on the Distribution Value Chain Model of Independent Feature Films in the UK. International Journal on Media Management. v. 17, n. 2, p. 93-108, 2015.

LADSON, N.; LEE, A. M. Strategic Media Venturing:Corporate Venture Capital Approaches of TIME Incumbents. International Journal on Media Management, v. 19, n. 2, p. 144-163, 2017.

LEE, A. M.; CHYI, H. I. The Rise of Online News Aggregators: consumption and competition. International Journal on Media Management, v. 17, n. 1, p. 3-24, 2015.

LORIGUILLO-LÓPEZ, A. Crowdfunding Japanese Commercial Animation: Collective Financing Experiences in Anime. International Journal on Media Management, v. 19, n. 2, p. 182-195, 2017.

LOWE, G. F.; Berg, C. E. The Funding of Public Service Media: A Matter of Value and Values. International Journal on Media Management, v. 15, n.2, p. 77-97, 2013.

MAIJANEN, P.; JANTUNEN, A. Centripetal and Centrifugal Forces of Strategic Renewal: The Case of the Finnish Broadcasting Company. International Journal on 
Media Management, v. 16, n. 3-4, p. 139-159, 2014.

MEYER, K. M.; TANG, T. \#SocialJournalism: Local News Media on Twitter. International Journal on Media Management, v. 17, n. 4, p. 241-257, 2015.

MIERZJEWSKA, B. I.; HOLLIFIELD, C. A. Theoretical approaches in media management research. In: ALBARRAN, A. B.; CHAN-OLMSTED, S. M.; WIRTH, M. O. (orgs.). Handbook of Media Management and Economics. Abingdon: Routledge, 2006. p. 37-65. Disponível em: https://www.routledgehandbooks.com/ doi/10.4324/9781410615589.ch3. Acesso em: 12 ago. 2016.

$\therefore$ SHAVER, D. Key Changes Impacting Media Management Research. International Journal on Media Management, v. 16, n. 2, p. 47-54, 2014.

MINTZBERG, H.; RAISINGHANI, D.; THÉORÊT, A. The Structure of "Unstructured" Decision Processes. Administrative Science Quarterly. v. 21, n. 2, p. 246-275, jun. 1976.

NAG, R., HAMBRICK, D. C., CHEN, M-J. What is strategic management, really? Inductive derivation of a consensus definition of the field. Strategic Management Journal, v. 9, n. 28, p. 935-955, 2007.

NEE, R. C. Creative Destruction: An Exploratory Study of How Digitally Native News Nonprofits Are Innovating Online Journalism Practices. International Journal on Media Management, v. 15, n.1, p. 3-22, 2013.

OLIVER, J. J. Media Management Tools: UK Broadcast Media Executives' Perspective. International Journal on Media Management, v. 15, n.4, p. 245-257, 2013.

PAPADIMITRIOU, L. Transitions in the Periphery: Funding Film Production in Greece Since the Financial Crisis. International Journal on Media Management, v. 19, n. 2, p. 164-181, 2017.

PARNELL, Gregory S., BRESNICK, Terry A., TANI, Steven N., JOHNSON Eric R. Handbook of Decision Analysis. New Jersey: Wiley, 2013.

PICARD, R. G. Environmental and Market Changes Driving Strategic Planning in Media Firms. In: PICARD, R. G. (Org.). Strategic Responses to Media Market Changes. Jönköping International Business School, 2004. p. 1-17. Disponível em: http:// www.robertpicard.net/PDFFiles/environandmktchanges.pdf. Acesso em: 12 ago. 2016.

Shifts in newspaper advertising expenditures and their implications for the future of newspapers. Journalism Studies, v. 9, n. 5, p. 704-716, 2008.

PORTER, M. E. Competitive Advantage: creating and sustaining competitive performance. New York: Free Press, 1985.

POTTER, A. Funding Contemporary Children's Television: How Digital Convergence Encourages Retro Reboots. International Journal on Media Management, v. 
19, n. 2, p. 108-122, 2017.

POUTANENA, P.; LUOMA-AHOB, V.; SUHANKOB, E. Ethical Challenges of Hybrid Editors. International Journal on Media Management, v. 18, n. 2, p. 99-116, 2016.

SANCHEZ, J. L. M. (org.) Empresa informativa XXI. Madrid: Editorial Sintesis, 2017.

SCHULTZ, C. J.; JONES, M. You Can't Do That! A Case Study of Rural and Urban Media Entrepreneur Experience. International Journal on Media Management, v. 19, n. 1, p. 11-28, 2017.

SOLOSKI, J. Stability or Rigidity: Management, Boards of Directors, and the Newspaper Industry's Financial Collapse. International Journal on Media Management, v. 17, n. 1, p. 47-66, 2015.

TENNANT, J. I. Free Newspapers in the United States: Alive and Kicking. International Journal on Media Management, v. 16, n. 3-4, p. 105-121, 2014.

Recebido em: 16/11/2017

Aceito em: 08/03/2018

Dados dos autores

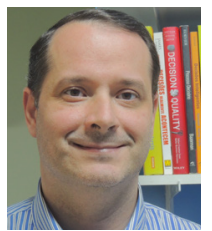

Fabiano Rodrigues | frodrigues@espm.br

Doutor em Administração pela Universidade de São Paulo (USP). Mestre e bacharel em Engenharia de Produção pela USP. Professor adjunto e pesquisador no Programa de Mestrado Profissional em Produção Jornalística e Mercado (MPPJM) da Escola Superior de Propaganda e Marketing (ESPM-SP).

Endereço do autor:

Escola Superior de Propaganda e Marketing - ESPM SP

Rua Doutor Álvaro Alvin, 123

04018-010 - São Paulo (SP) - Brasil

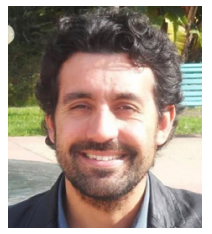

Edson Capoano | edson.capoano@espm.br

Doutor em Integração da América Latina pela Universidade de São Paulo (USP). Mestre em Comunicação

e Semiótica pela Pontifícia Universidade Católica de São Paulo (PUC-SP). Bacharel em Jornalismo pela

PUC-SP. Professor adjunto e pesquisador no Programa de Mestrado Profissional em Produção Jornalística e

Mercado (MPPJM) da Escola Superior de Propaganda e Marketing (ESPM-SP).

Endereço do autor:

Escola Superior de Propaganda e Marketing - ESPM SP

Rua Doutor Álvaro Alvin, 123

04018-010 - São Paulo (SP) - Brasil

Contribuições dos autores: Ambos os autores fizeram contribuições substanciais para concepção, desenvolvimento, redação e revisão crítica do trabalho; e aprovação final da versão para publicação. 